\title{
The Implicit Ethics of Power in the Landscape of Systems Implementation Policy
}

\author{
Konrad Peszynski and John Lenarcic \\ School of Business Information Technology, RMIT University, \\ Melbourne, Australia
}

Konrad.Peszynski@rmit.edu.au John.Lenarcic@rmit.edu.au

\begin{abstract}
With the damaging influence of systems implementation failure, it is vital to distinguish the issues surrounding large-scale software selection, construction and operations. Using the work by Markus (1983) as a touchstone, this paper spotlights the question of resistance towards a new system and the impact policy has on minimising confrontation. A case study delving into the lines of conflict associated with the selection and implementation of an enterprise-wide student learning management system is presented and discussed in detail. A brief assessment of the findings from this analysis and Markus (1983) is made. It was revealed that the ratification of policy leads to an embedded compliance of power frameworks. These dynamic hierarchies elicit discourse patterns that serve to constrain defiance.
\end{abstract}

Keywords: Resistance, Policy, Power, Discourse, Systems Implementation 